\title{
Make disturbance your friend
}

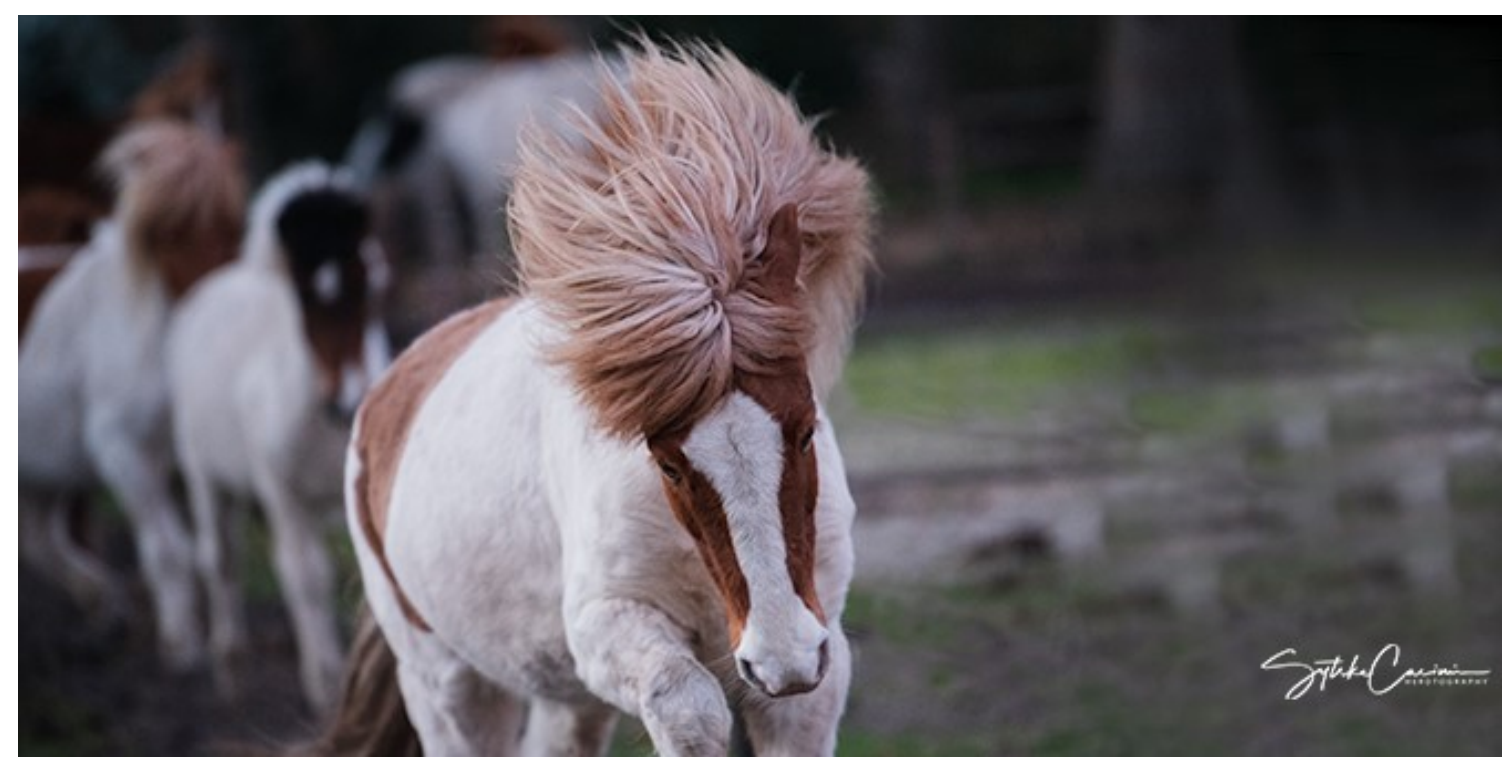

The crisis of the Covid-19 pandemic, unprecedented in modern times, is having a devastating impact on lives and livelihoods. At the time of writing, 4.5bn people around the world are in "lockdown" - an emergency protocol of forced self-isolation and social distancing to avoid the high rate of transmission. This while our medical and scientific community scrambles to provide life-saving treatment that can get our communities and economies back on track. In this extraordinary global anthropological event, many questions are being asked of our society: how come we are in this situation; what light is Covid-19 shining on our underlying mind-sets and behaviour; is how we run our political institutions, economies and communities today something to be proud of; will we come out of this a changed world, and, a world for the better?

In this series of articles, our aim is to ask questions about how we and our leaders are handling change within this disruptive challenge, and to offer frameworks of thinking and practice that might enable us to handle this crisis effectively - as after all, who knows in this unprecedented situation what "right" looks like.

In our previous article, Being Before Doing, we looked at how leaders need to be in change, attending to the quality of their inner state. In this, the third article, we explore what - from that inner spaciousness of being - leaders can do to lead change successfully.

There is much discourse now about the skills of our political leaders in handling the crisis. In a sense, we are all part of a grand global soup of leadership learning. Our research shows that in highly dynamic scenarios, leadercentric leadership - the notion that without the leader calling the shots nothing can happen - does not lead to success. A finding which may surprise some, since in a crisis, pace-setting heroic leadership is so often the default reaction. Leading change, especially in a highly volatile environment, asks instead for a leader to step back and create capability in the system around them to handle change, using a set of four interdependent practices that strike a balance between creating stabilising structures and disrupting routines - making disturbance your friend. If these practices are not all in play, disturbance can be your enemy, creating debilitating anxiety in others, while tempting leaders to react by over-protecting people, stifling their initiative.

The four practices we have found leaders need to deploy to create movement (and not just busy action) are: Attractor - creating a pull towards an aligning purpose; Edge and Tension - amplifying disturbance by facing reality; Container - channelling anxiety towards productive energy; and Transforming Space - creating movement in the here-and-now. Two of these, Attractor and Container, create stability and structure, while Edge and Tension and Transforming Space amplify the necessary disturbance. 
While all four are needed in this alchemy of how to lead big change well, it is Edge and Tension, the calm yet straight-talking naming of reality, that has the highest correlation to success (explaining just over half of the reason why big change succeeds or fails). And yet, it is also the practice we consistently see leaders and organisations struggle with - naming difficult truths is not easy.

This has certainly been a herculean task for our political leaders in the past few weeks as they face up to the Covid19 pandemic. And it can be done well - just see how the governor of New York, Andrew Cuomo, has been winning plaudits for his calm yet uncompromising naming of reality ("facts are empowering"). Closer to our homes in Europe, we have been following how our leaders act in the face of the virus' profound health impact and social and economic disruption, and started by analysing a sample of the key early speeches of German Chancellor Angela Merkel, Dutch Prime Minister Mark Rutte, and the UK's Prime Minister Boris Johnson. In their speeches we looked for evidence of the required leadership practices (of course, we recognise that their speeches are created to a large extent by their advisors; however, they are illustrative and indicative of their leadership stance).

We consciously chose to look at these leaders appreciatively, to explore what the evidence of these practices reveals since we are keenly aware of the negative projections attracted by leaders in this time. We also invite you to notice whether and how you have used these practices in your approach to the crisis - especially if you have been leading others; where have you excelled, and what has felt most daunting? Should you feel yourself more in judgement of our public leaders, you may want to be curious about what that might tell you about yourself, owning any projection of what might feel unwanted or disregarded in you.

Back to the speeches. Given the primacy of straight-talking leadership in change, it was reassuring to see that, overall, Edge and Tension was the second most evidenced practice. All leaders were clear on the seriousness of the challenge and the reality in which we find ourselves. "Together we are faced with a challenge of enormous proportions" (Rutte). And all three informed us that this challenge, which will cause financial hardship, will last months rather than weeks. Edge and Tension needs to be sustained in change (no matter how tempting it is for leaders to say, "we are winning, there is light at the end of the tunnel"). A few weeks on from those early speeches, Merkel, even while looking at careful steps toward an exit strategy, still warns the current situation is "a fragile and provisional success". Meanwhile Rutte has been warning people not to expect a swift return to normal as his government prepares to brief the country on 21 April.

Not surprisingly, the leadership practice of Container - the calm assuring presence showing that disturbance and difficulty can be faced - was the most used practice throughout the early speeches. Often in difficult times we see Container leadership move into its shadow - ignoring the reality, overly-protecting or over-promising that troubles will be short-lived (and we have certainly seen this displayed in other political leaders on the world stage right now.) Yet these three nations' leaders created a strong interplay between Edge and Tension and Container, ensuring that difficult truths did not tip into scare-mongering, and that calm assuredness did not tip into false security. Just listen to Merkel, "You can rely on the fact that delivery of household supplies will be assured, and even when the supermarket shelves may be empty sometimes, they will be filled again." All three leaders said they would do all in their power to support those who would be affected by the consequences, and they also were honest that it would not be easy. They provided just enough safety to keep us grounded, without creating a false, irrational sense of invulnerability - which can feel far less safe (as some of us may have anxiously felt when we were told Boris Johnson was fit and well while entering an ICU...).

In analysing the speeches for Attractor practice - creating an emotionally compelling shared narrative for what action is required - the leaders' direction and intention were clear, we can beat this virus, but only when we all do it together, Johnson saying "in this fight there can be no doubt that each and every one of us is enlisted", and follow certain imperatives, "stay at home, protect the NHS, save lives". All three leaders avoided the seductive shadow of Attractor, depicting charismatic images about a future promised land, which of course no leader can reliably do at the start of a major change, especially a disruptive one of which we cannot know the outcome, and at a time when many of us will still be dealing with grief and not yet ready to hear about the future. Still, meaning matters and this was borne out by all three leaders. 
The most uplifting and surprising element of the speeches was perhaps how all of them created a Transforming Space, changing the now. This practice is tricky since it only holds value in the presence of the other three, otherwise it can appear as all fizz and pop - even, Svengali-like leadership. When alongside the others Transforming Space profoundly moves people in the moment, indeed these speeches in and of themselves are transforming spaces, given that none of the leaders had had prior cause to give such a speech, and the simple act of giving them creates a vulnerability.

Just look at not only how they have spoken, but also how they have acted. The moment Rutte made the mistake of wanting to shake the hand of the government's expert virologist - just after he had announced it was recommended to no longer shake hands - was in our eyes not a moment of incongruence but a perfect though unintentional modelling of the mindset change we would all need to make: the act of him needing to be corrected made it easier for us all to correct others. More recently, we have most clearly seen the powerful impact of Transforming Space when Boris Johnson spoke directly of the NHS saving his life. His modelling of his humanity, mortality and self-care, by taking time to heal, invites us to meet those parts of ourselves too. We anticipate that this experience may also in the longer run affect political choices to be made.

We cannot know yet which countries - and which leadership approaches - will be successful in these Covid-19 times. Indeed, we may still need to define what success looks like. Numbers that look good today may not tomorrow, and numbers are in any case only a small part of the story. While the graphs we see show that Germany, the UK and the Netherlands hover around an infection transmission rate of 1 , a number that is to be vastly preferred to the 2,5 or above where they came from, we cannot say they are a success (yet). These times provide us with opportunities for leadership reflections, reflections in which it will be helpful to remain in a space of curious and intentional responding. We notice the seduction of easy answers - those who follow our research will succeed, women national leaders are more successful than men.

While we need clarity in crisis, we do our best to hold our own theories lightly - realising that success will not always be clear in the middle phase, so staying present to what is continuously changing. In the initial weeks of this crisis the Still Moving community used our WhatsApp group as a Container, and that in turn spurred us on to write these articles. Indeed, writing this series of articles about leadership during the Covid-19 crisis acts as a Container, allowing us to conduct present-moment sense making as well as channel our energy towards the future. At the same time, we acknowledge with Edge and Tension that we are not sure what our role is now or will be in the future as some of our clients are stopping work, and change consultancy - while perhaps needed more than ever - may not be the first port of call for cash-worried companies.

Nonetheless, through all this uncertainty we remember the Attractor image of our purpose, created several years ago as we gathered as a collective of change consultants, and that is of a lighthouse. In these times that Attractor image allows us to hold on to the sense that all we can do in this turbulent time is reveal what is, we don't have to solve it; lighthouses are built for storms - in fact that's when they come into their own - and while this storm is certainly creating plenty of discomfort, it is also inviting us to review who we are as a group and how we work beyond our client work. Though we have often spoken of it, this is the first time we are writing an article jointly (itself a Transforming Space). While we may not always like it we have come to know disturbance as our friend. We would love to hear from you, what gifts has disturbance given you, what has it allowed you to cultivate?

Notes:

- This blog post expresses the views of its author(s), not the position of LSE Business Review or the London School of Economics.

- This is the third in a series of four articles (first part; second part)

- Featured image: Courtesy @ Sytske Casimir sytske@still-moving.com, NOT under Creative Commons. All rights reserved.

-When you leave a comment, you're agreeing to our Comment Policy 


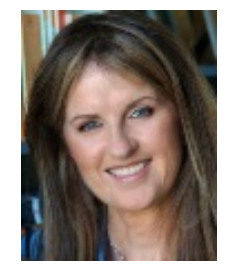

Deborah Rowland has led change in major global corporations including BBC Worldwide, Gucci Group, PepsiCo and Shell, where she had vice-president of organisational development and group HR director roles. She is the author of Still Moving: How to Lead Mindful Change (Wiley 2017) and co-author of Sustaining Change: Leadership That Works (Wiley 2008). Deborah founded the change consultancy Still Moving, where she advises institutional leaders around the world on how to implement change in more effortless ways. She also speaks, writes, and teaches on the subject. In the 2017 Thinkers50 Radar she was named one of the new generation of management thinkers changing the world of business. She tends to her own inner game via regular yoga, meditation and art gazing, painting, and walks in nature, in particular along the spectacular coastal paths of Southern Cornwall.

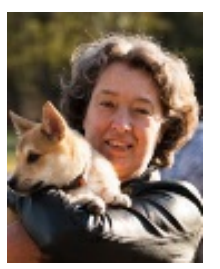

Sytske Casimir is a horsewoman, coach, poet and photographer who has worked in and with large international organisations on leadership development and change for almost 20 years. She is a member of the founding group of Still Moving Consultancy, a tribe of change practitioners passionate about bringing mindful leadership into the world. Her work tends to take the form of facilitating dialogues, dialogues between persons in a team, parts of an organisation or parts of a person. She enjoys co-creating spaces where people can show up fully, find what they don't know they know and (re)discover what inspires them. Helping make meaning of patterns which may so far have been unconscious. This isn't always an easy process, at times we may feel lost, and it is through being lost that we can re-find ourselves and our way. 